\title{
Diagnostic, therapeutic and evolutionary characteristics of cervical cancer in Department of Radiotherapy, Mohamed V Military Hospital - Rabat in Morocco
}

Mohammed Elmarjany ${ }^{1}$, Abdelhak Maghous ${ }^{2 *}$, Rachid Razine ${ }^{3}$, Elamin Marnouche², Khalid Andaloussi ${ }^{1}$, Amine Bazine ${ }^{1}$, Issam Lalya ${ }^{1}$, Noha Zaghba ${ }^{1}$, Khalid Hadadi ${ }^{1}$, Hassan Sifat', Baba Habib ${ }^{4}$, Jaouad Kouach ${ }^{4}$ and Hamid Mansouri ${ }^{1}$

\begin{abstract}
Background: Cancer of uterine cervix is the second most common cause of cancer related deaths among women. The aim of this study is to report the experience of Military Hospital Mohamed $V$ in the management of cervical cancer and their results.

Methods: All cervical cancer managed at the radiotherapy department of Military Hospital Mohamed $\mathrm{V}$ between January 2005 and February 2010, were included for investigation of their demographic, histological, therapeutic and follow-up characteristics. Of the 162 cases managed, 151 (93.2\%) cases were treated in our department.

Results: In our study the median age was 51.5 years (33-82). The median duration of symptoms before diagnosis was four $[3,7]$ months. The major presenting complaints were abnormal vaginal bleeding (89.8\%). Squamous cell carcinoma cervix was seen in $86.2 \%(n=137)$, adenocarcinoma in $11.3 \%(n=18)$ and adenosquamous carcinoma in $2.4 \%(n=4)$. One hundred seventeen (84.8\%) cases were seen at late stage. An abdominal and pelvic computed tomography $(\mathrm{CT})$ scan was performed in $34.6 \%(n=56)$ of cases, magnetic resonance imaging (MRI) in $62.9 \%$ $(n=102)$. The pelvic lymph nodes were achieved in $16.6 \%$ of cases.

Over half of patients $58.3 \%(n=88)$ were treated with a combination of external beam radiation therapy (EBRT) and a concurrent cisplatin based chemotherapy (40 mg $/ \mathrm{m} 2$ weekly).

With a mean of 51.6 months (2 to 109), we recorded 19 (12.6\%) pelvic relapse and 15 (9.9\%) metastases. The median time to onset was 19.4 months (2-84 months). The local control rate was $63.6 \%(n=96)$ and 21 (13.9\%) patients were lost to follow-up. The overall survival (OS) at 3 years and 5 years was respectively $78.3 \%$ and $73.6 \%$ and the relapse-free survival (RFS) was respectively $80 \%$ and $77.2 \%$.

Conclusion: Most of cervical cancer patients in Morocco are seen at late stage necessitating referral for radiotherapy, chemotherapy or palliative care. This may reflect lack of cervical screening in order to early detect and treat pre-malignant disease stage.
\end{abstract}

Keywords: Cancer of uterine cervix, Radiotherapy, Concomitant radio-chemotherapy

\footnotetext{
*Correspondence: magabdelhak@gmail.com

${ }^{2}$ National Institute of Oncology, Rabat, Morocco

Full list of author information is available at the end of the article
} 


\section{Background}

Cervical cancer is the second most common cancer in women worldwide [1]. It is estimated that there are more than 529000 new cases diagnosed annually and more than 274,000 deaths in the world in 2008, of which more than $87 \%$ occur in developing countries [2, 3]. Cervical cancer continues to be related to socioeconomic and demographic (SEDS) disparities in both developing and developed countries. In the U.S., although the overall downward trend in cervical cancer there still exists a disproportion in mortality rates for cervical cancer related deaths among ages, racial, geographic and socio-economic groups [4, 5]. Analyses of the USA cancer data have shown that mortality due to cervical cancer increases with poverty and decreasing education [6]. Studies have publicized that late stage at diagnosis is correlated with lower survival rates [7]. It has also been reported that longer durations of symptoms as well as of treatment prolongation negatively affect survival $[8,9]$. These two factors can therefore be useful predictors for the severity of illness and likelihood of survival.

In Morocco, cervical cancer is the second most common cancer of women after breast cancer [10]. According to GLOBOCAN 2008 [2], the world age-standardized incidence of cervical cancer among women in Morocco was 14.1 new cases/100 000 inhabitants/year (1979 new cases/ year). The mortality rate from this cancer was 8.4 per 100 000 . The stage of diagnosis is the most important independent factor of prognosis $[11,12]$. In Morocco, a recent study [13] showed a late diagnosis of cervical cancer. Indeed, $43.7 \%$ were presented with stage II at diagnosis (FIGO) and $38.1 \%$ were presented in advanced stages (stages III and IV).

The aim of this study is to report the experience of Military Hospital Mohamed V in the management of cervical cancer, the various treatment modalities used and their results.

\section{Methods}

This is a retrospective analytic study of 162 cervical cancer patients managed at the radiotherapy department of Military Hospital Mohamed V of Rabat in Morocco, between January 2005 and February 2010.

Data was collected using a well structured checklist containing important study parameters. The record collection includes patient demographic data (age of diagnosis, of marriage and age of first pregnancy (years)), menopausal status (premenopausal or postmenopausal) and parity was separated on three groups $(0,1-4$ and $\geq 5)$. Data includes also clinical presenting symptoms (abnormal vaginal bleeding, offensive vaginal discharge, pelvis pain...), duration of symptoms (months), vaginal invading (free, upper, medium or lower vaginal wall) and other clinical data such as classification FIGO of disease (IA, IB, IIA, IIB, IIIB, IVA, IVB), histological type (squamous, adenocarcinoma or adenosquamous), pelvic and/or lateral aortic adenopathy, parametrial invasion, date of primary diagnosis. The type and modalities of primary treatment (radiotherapy, chemotherapy, both or/and surgery), date and sites of relapse (pelvic and/or metastases), the follow up data, death date and date of last follow-up visit were also recorded.

Statistical analysis of the data was carried out by the SPSS for Windows (SPSS, Inc., Chicago, IL, USA). Qualitative variables were presented as number and percentages. Quantitative variables were presented as mean \pm standard deviation for variables with normal distribution, and as median and interquartile range (IQR) for variables with skewed distributions. The survival rate was analyzed with the Kaplan-Meier method.

\section{Results}

Of the 162 cases of cervical cancer managed, 151 $(93.2 \%)$ cases were treated in our department. Table 1 shows their epidemiological characteristics. Their ages ranged from 33 to 82 years old with a mean of 51.5 $( \pm 11.5)$ years. More than half of patients were post menopausal 85 (52.5\%) and married early 58 (63.7\%). Age of first pregnancy ranged from 14 to 36 with a mean of $20.3( \pm 4.2)$. Also, their parity ranged from 0 to 12 with a mean of $4.9( \pm 2.6)$.

Abnormal vaginal bleeding was the most common symptom reported by 143 (89.9\%) patients. Other symptoms were offensive vaginal discharge 91 (57.2) and pelvic pain 44 (27.7). The median duration of symptoms before diagnosis was four months $[3,7]$. Tumor size was $4.8 \mathrm{~cm}( \pm 1.6)$ clinically and in $64(57.7 \%)$ patient's upper vaginal wall was invaded. Squamous cell carcinoma 137 (86.2 \%) was the leading histological type, whereas adenocarcinoma contributed $18(11.3 \%)$ and 4 (2.5\%) were adenosquamous carcinoma.

An abdominal and pelvic CT was performed in $34.6 \%$ $(n=56)$ of cases, MRI in $62.9 \%(n=102)$. The pelvic lymph nodes were achieved in $16.6 \%$ of cases. In MRI Tumor size was $41.6( \pm 16.8) \mathrm{mm}$ and parametrial was invaded in 57 (55.9\%) of cases.

Based on International Federation of Gynaecology and Obstetrics classification for staging cervical cancer (ACS, 2008), 2 (1.4\%), 17 (12.3\%), 18 (13\%), 5 (3.6 \%), 31 (22.5\%), 27 (19.6\%), 3 (2.2\%), 29 (21\%), 4 (2.9\%) and $2(1.4 \%)$ of cases, cancer stages were respectively IA, IB1, IB2, IIA, IIB proximal, distal IIB, IIIA, IIIB, VIA and VIB (Fig. 1).

One hundred fifty one $(93.2 \%)$ cases were treated in our department. Table 2 shows their modalities. Over half of patients $58.3 \%(n=88)$ were treated with a combination of external beam radiation therapy (EBRT) and 
Table 1 Clinical and para-clinical epidemiological characteristics $(n=162)$

\begin{tabular}{|c|c|c|c|}
\hline Item & Frequency (\%) & Range & $\begin{array}{l}\text { Mean ( } \pm \text { standard } \\
\text { deviation) }\end{array}$ \\
\hline Age of diagnosis (years) & & $33-82$ & $51.5( \pm 11.5)$ \\
\hline$\leq 39$ & $21(12.9)$ & & \\
\hline $40-49$ & $61(37.6)$ & & \\
\hline $50-59$ & $45(27.7)$ & & \\
\hline $60-69$ & $18(11.1)$ & & \\
\hline$\geq 70$ & $17(10.5)$ & & \\
\hline
\end{tabular}

Menopausal status

Premenopausal $\quad 77(47.5)$

Postmenopausal $\quad 85(52.5)$

Age of marriage (years)

$\leq 18$

$12-30 \quad 17.9( \pm 3.6)$

$>18$

Age of first pregnancy (years)

Parity

0

$1-4$

$\geq 5$

Duration of symptoms (months)

Presenting complaints

Abnormal vaginal
bleeding
Offensive vaginal
discharge
Pelvic pain
Haematuria

Clinically review

Tumor size $(\mathrm{cm})$

Vaginal invading

$\begin{array}{ll}\text { Upper } & 64(57.7) \\ \text { Medium } & 15(13.5) \\ \text { Lower } & 4(3.6) \\ \text { Free } & 28(25.2) \\ \text { Parametrial invasion } & 95(67.4) \\ \text { Histological type } & \\ \begin{array}{l}\text { Squamous cell } \\ \text { carcinoma }\end{array} & 137(86.2) \\ \text { Adenocarcinoma } & 18(11.3) \\ \text { Adenosquamous } & 4(2.5) \\ \text { carcinoma } & \\ \text { Para clinical review } & \\ \text { Abdominal and pelvic } & 56(34.6) \\ \text { CT } & \\ \text { Pelvic adenopathy } & 12(21.4)\end{array}$

Table 1 Clinical and para-clinical epidemiological characteristics ( $n=162)$ (Continued)

\begin{tabular}{|c|c|c|}
\hline $\begin{array}{l}\text { Lateral aortic } \\
\text { adenopathy }\end{array}$ & $1(1.8)$ & \\
\hline Pelvic MRI & & $41.6( \pm 16.8)$ \\
\hline Tumor size (mm) & $102(93)$ & \\
\hline Pelvic adenopathy & $16(15.7)$ & \\
\hline Parametrial invasion & $57(55.9)$ & \\
\hline Hemoglobin $(\mathrm{g} / \mathrm{dl})$ & & $11.8( \pm 1.8)$ \\
\hline
\end{tabular}

a concurrent cisplatin based chemotherapy $(40 \mathrm{mg} / \mathrm{m} 2$ weekly). Fifty (34\%) patients underwent surgery as their initial treatment. Forty six (31.4\%) of these received post operative radiotherapy or concomitant radio-chemotherapy following surgery due to positive pelvic lymphnodes, narrow or positive surgical margins or other poor risk factors. The surgical procedure was Piver II; a modified radical hysterectomy with annexectomy, which includes removal of the uterus, cervix, upper one-fourth of the vagina, and parametria. The surgeon also performs a bilateral pelvic lymphadenectomy via laparotomy in 57 $(85.1 \%)$ cases, who brought $4.7 \pm 3.9$ nodes on the right and $4.1 \pm 3.7$ nodes on the left, of which was only invaded in 18/471 (3.82\%). Conventional laparoscopy or robot-assisted laparoscopy was not available in our hospital.

Table 3, summarizes the various therapeutic modalities of different stages. Essentially our series contains 87 $(63.1 \%)$ patients with stage IIB and IIIB. These two stages are essentially treated with concomitant radiochemotherapy.

With a mean follow-up of 51.6 months (2 to 109), we recorded 19 (12.6\%) pelvic relapse and 15 (9.9\%) metastases. The median time to onset was 19.4 months [2-33] and [34-84]. The local control rate was $63.6 \%(n=96)$ and $21(13.9 \%)$ patients were lost to follow-up. The overall survival (OS) at 3 years and 5 years was respectively $78.3 \%$ and $73.6 \%$ and the relapse-free survival (RFS) was

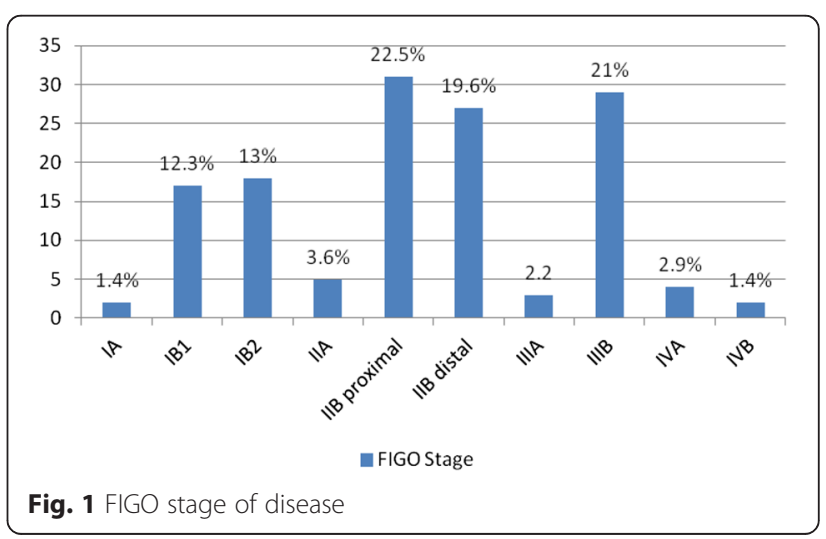


Table 2 Therapeutic modalities $(n=151)$

\begin{tabular}{ll}
\hline Therapeutic modalities & Frequency (\%) \\
\hline Concomitant radio-chemotherapy & $66(43.7)$ \\
Concomitant radio chemotherapy followed by surgery & $22(14.9)$ \\
Exclusive radiotherapy & $12(7.9)$ \\
Surgery followed by exclusive radiotherapy & $25(16.6)$ \\
Surgery followed by concomitant radio chemotherapy & $21(13.9)$ \\
Surgery alone & $4(2.6)$ \\
Palliative chemotherapy & $1(0.7)$ \\
\hline
\end{tabular}

respectively $80 \%$ and $77.2 \%$ (Fig. 2). We tried to contact all patients who were lost to follow-up by phone and by sending correspondence letter without resulting from response.

As shown in Table 4, univariate analysis for clinical parameters as risk factors for relapse, the only independently significant variables were the Menopausal status $(p=0.043)$ and parity $(p=0.010)$. Women with advanced cervical cancer (distal IIB, III and IV) have a higher rate of relapse $16(25.8 \%)$ than those with early stage disease (I, IIA and proximal IIB) but there's statistically no significant.

Multivariate analysis was not performed for our patient because of the small number of events.

\section{Discussion}

Cervical cancer has continued to have a devastating impact on women's health globally, and particularly in developing countries like Morocco where it has remained the second most common cancer of women after breast cancer [10].
The demographic characteristics of the patients in this study share similarities with results from several other centers in Morocco and North Africa. For instance, the mean age of patients in this study was $51.5( \pm 11.5)$ years and the high mean parity $4.9( \pm 2.6)$ agrees with the results from other studies [14, 15]. Elsewhere in Africa, the mean age was lower: 35 years in Dakar and 48 years in Burkina Faso [16] and Madagascar [17]. The older mean age in our study probably indicates a later exposure to risk factors or reflects the belated consultation and the lack of screening. These findings affirm that menopausal status and grand multiparity were significant causal risk factor for relapse.

The presenting complaints were essentially similar to the reports in the literatures reviewed. The higher incidence of abnormal vaginal bleeding reported in literature, affirm that is an important sign in cervical cancer. Abnormal vaginal bleeding normally occurs as postcoital, inter-menstrual, or postmenopausal bleeding. Should every case of abnormal vaginal bleeding be promptly investigated, cervical cancers would be diagnosed in early stages, at a time when there could be hopes of cure. However, due to the illiteracy, poverty, ignorance, non-utilization of screening services, the majority of the women present in late stage disease [13]. Initial evaluation of lymph nodes is commonly performed with CT or RMI to minimize expense, biopsy of suspected lymph nodes was not performed because it is not a standard in cervical cancer but PET and PET/CT are the imaging modalities used to provide information for treatment decisions [18-21]. In our study, no patients have PET because we do not have a pet scan this period. Actually, since 2012, we perform a PET/CT prior

Table 3 Therapeutic modalities based on clinical stage

\begin{tabular}{|c|c|c|c|c|c|c|c|c|c|c|}
\hline \multirow[t]{2}{*}{ Modalities } & \multicolumn{10}{|c|}{ FIGO stage } \\
\hline & $\| A$ & $\mid A$ & $\mid \mathrm{B} 1$ & IB2 & $\| A$ & IIB proximal & IIB distal & $\| \mathrm{II}$ & IVA & IVB \\
\hline \multirow[t]{2}{*}{ Exclusive radiotherapy } & 0 & 0 & 2 & 0 & 0 & 0 & 3 & 5 & 2 & 0 \\
\hline & $0,0 \%$ & $0,0 \%$ & $16,7 \%$ & $0,0 \%$ & $0,0 \%$ & $0,0 \%$ & $25,0 \%$ & $41,7 \%$ & $16,7 \%$ & $0,0 \%$ \\
\hline \multirow[t]{2}{*}{ Concomitant radio-chemotherapy } & 2 & 0 & 1 & 7 & 1 & 18 & 18 & 16 & 1 & 1 \\
\hline & $3,1 \%$ & $0,0 \%$ & $1,5 \%$ & $10,8 \%$ & $1,5 \%$ & $27,7 \%$ & $27,7 \%$ & $24,6 \%$ & $1,5 \%$ & $1,5 \%$ \\
\hline \multirow{2}{*}{$\begin{array}{l}\text { Surgery followed by exclusive } \\
\text { radiotherapy }\end{array}$} & 0 & 1 & 10 & 3 & 0 & 3 & 0 & 0 & 0 & 0 \\
\hline & $0,0 \%$ & $5,9 \%$ & $58,8 \%$ & $17,6 \%$ & $0,0 \%$ & $17,6 \%$ & $0,0 \%$ & $0,0 \%$ & $0,0 \%$ & $0,0 \%$ \\
\hline \multirow{2}{*}{$\begin{array}{l}\text { Surgery followed by concomitant } \\
\text { radio chemotherapy }\end{array}$} & 0 & 0 & 3 & 4 & 1 & 0 & 0 & 0 & 0 & 0 \\
\hline & $0,0 \%$ & $0,0 \%$ & $37,5 \%$ & $50,0 \%$ & $12,5 \%$ & $0,0 \%$ & $0,0 \%$ & $0,0 \%$ & $0,0 \%$ & $0,0 \%$ \\
\hline \multirow{2}{*}{$\begin{array}{l}\text { Concomitant radio chemotherapy } \\
\text { followed by surgery }\end{array}$} & 1 & 0 & 0 & 2 & 2 & 9 & 5 & 3 & 0 & 0 \\
\hline & $4,5 \%$ & $0,0 \%$ & $0,0 \%$ & $9,1 \%$ & $9,1 \%$ & $40,9 \%$ & $22,7 \%$ & $13,6 \%$ & $0,0 \%$ & $0,0 \%$ \\
\hline \multirow[t]{2}{*}{ Surgery alone } & 0 & 1 & 0 & 1 & 0 & 0 & 0 & 0 & 0 & 0 \\
\hline & $0,0 \%$ & $50,0 \%$ & $0,0 \%$ & $50,0 \%$ & $0,0 \%$ & $0,0 \%$ & $0,0 \%$ & $0,0 \%$ & $0,0 \%$ & $0,0 \%$ \\
\hline \multirow[t]{2}{*}{ Palliative chemotherapy } & 0 & 0 & 0 & 0 & 0 & 0 & 0 & 0 & 0 & 1 \\
\hline & $0,0 \%$ & $0,0 \%$ & $0,0 \%$ & $0,0 \%$ & $0,0 \%$ & $0,0 \%$ & $0,0 \%$ & $0,0 \%$ & $0,0 \%$ & $100,0 \%$ \\
\hline
\end{tabular}



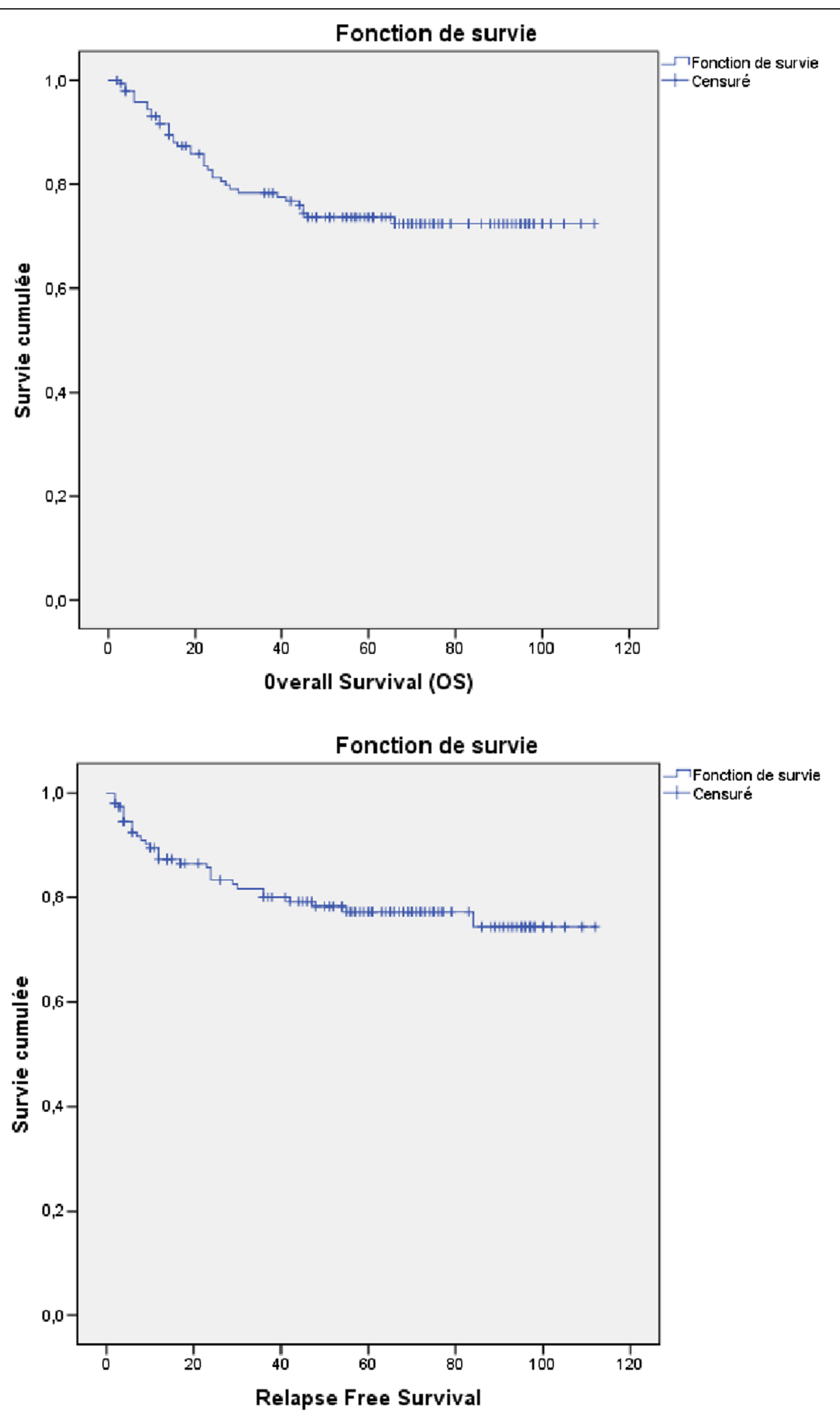

Fig. 2 Global survival (GS) and relapse free survival (RFS) 
Table 4 Univariate analysis for clinical parameters associated with the occurrence of relapse and/or metastasis

\begin{tabular}{llll}
\hline Characteristic & \multicolumn{2}{l}{ Pelvic relapse and/or metastases } & $P$ value \\
& Yes $(n=31)$ & No $(n=120)$ & \\
\hline Age & $47.97 \pm 10.317$ & $52.11 \pm 11.54$ & 0.071 \\
Menopausal status & & & 0.043 \\
$\quad$ Premenopausal & $20(27.4 \%)$ & $53(72.6 \%)$ & \\
$\quad$ Postmenopausal & $11(14.1 \%)$ & $67(85.9 \%)$ & \\
Age of marriage (years) & $18.57 \pm 2.84$ & $17.79 \pm 3.86$ & 0.393 \\
Age of first pregnancy (years) & $21.86 \pm 4.26$ & $19.97 \pm 4.97$ & 0.124 \\
Parity & $3.79 \pm 2.04$ & $5.19 \pm 2.65$ & 0.010 \\
Tumor size (cm) & $5.19 \pm 2.01$ & $4.62 \pm 1.50$ & 0.168 \\
Parametrial invasion & $21(22.1 \%)$ & $74(77.9 \%)$ & 0.596 \\
Histological type & & & 0.281 \\
$\quad$ Squamous cell carcinoma & $24(18.8 \%)$ & $104(81.2 \%)$ & \\
$\quad$ Adenocarcinoma & $6(35.3 \%)$ & $11(64.7 \%)$ & \\
Pelvic adenopathy & $4(23.5 \%)$ & $13(76.5 \%)$ & 0.658 \\
Hemoglobin (g/dl) & $11.62 \pm 1.61$ & $11.97 \pm 1.88$ & 0.448 \\
FIGO stage & & & 0.052 \\
I, IIA and proximal IIB & $8(12.3 \%)$ & $57(87.7 \%)$ & \\
Distal IIB, III and IV & $16(25.8 \%)$ & $46(74.2 \%)$ & \\
Therapeutic Modalities & & & 0.151 \\
Concomitant & $18(27.3 \%)$ & $48(72.7 \%)$ & \\
radio-chemotherapy & & $58(85.3 \%)$ & \\
Radio-surgery & $10(14.7 \%)$ & & \\
\hline
\end{tabular}

to treatment to evaluate the extent of disease with particular attention to lymph node metastases to provide information to design radiation fields.

This study confirmed a delayed diagnosis of cervical cancer in Morocco. In fact, the majority of patients were presented in advanced stage (IB2-IVA) 117 (84.8\%). The stage of diagnosis is the most important independent prognostic factor $[11,12]$ and the survival rate at 5 years decreases with stage of diagnosis: $85 \%$ for stage IB to 0$20 \%$ for stage IV [22]. The mortality rate from cervical cancer is greatly dependent on stage of diagnosis. In the same way, the risk of pelvic recurrence increases with the stage, $10 \%$ for stage IB to more than $75 \%$ for stage IV $[22,23]$. Finally, the risk of distant metastases also increases with the stage, respectively $16 \%, 26 \%, 39 \%$ and $75 \%$ for stages I, II, III and IV [24]. Early Clinical diagnosis has been responsible for the reduction of cervical cancer mortality achieved in developed countries before cervical screening programs were adopted [25-27].

Our pathological data joined those already described with the large predominance of squamous cell carcinoma [28, 29]; the most represented histological type in our study was squamous cell carcinoma 137 (86.2\%); adenocarcinomas in 18 (11.3\%) and adenosquamous cell carcinomas represented only 4 (2.5\%) of cervical cancer. Over the past 40 years, multiple reports have documented the increase in relative distribution of adenocarcinoma compared to SCC in developed countries [30, 31]. In the USA, from 1973 to 1977, the proportions of SCC and adenocarcinoma were $88 \%$ and $12 \%$, respectively; however, from 1993 to 1996, the proportions were $76 \%$ and $24 \%$ respectively [30].

In our study, treatment varied depending on the stage of diagnosis. Radiotherapy was indicated for the different stages. For advanced tumors ( $\geq$ stage II) concomitant chemotherapy was associated with radiotherapy and /or brachytherapy which join, in general, the recommendations for the management of invasive cervical cancer [32]. Whereas surgery was a part of treatment modalities in $71(47.7 \%)$ patients, which 50 (33.6\%) were operated before admission to our department without multidisciplinary consultation meetings. The reasons of surgery were intricate in our patients. It was indicated for very early stages (IA and IB2) in 15 (21.1\%) cases and for patients with adenocarcinoma in $14(19.7 \%)$ cases. It was also performed in $21(29.5 \%)$ case of poor response to concomitant chemoradiotherapy. Some locally advanced cervical cancer did not receive concomitant chemotherapy because of 6 (25\%) kidney failure and 11 (45.8\%) medical comorbidities or poor performance status associated.

In our population, the rate of relapse increased with the stage of diagnosis. This association shows the importance of early diagnosis. Morocco is endowed, since March 2010, of a National Plan for the Prevention and Control of Cancer (PNPCC). Screening and treatment of cervical cancer in Morocco represent the most crucial priorities for PNPCC. A screening program for cervical cancer is being introduced as well as other measures in order to improve the opportunities of access to early diagnosis by reducing geographical obstacles, multiply the number of centers of diagnosis confirmation, reduce economic barriers and provision facilities and resources. The installation of a screening program for cervical cancer will be based on infrastructure and personnel, primarily general practitioners, of primary level of health care delivery. A pilot mass screening performed in Lyon has clearly shown that intensive action, involving all local stakeholders including general practitioners, could reach a population of women who do not benefit from an adequate gynecological following-up [33].

We conducted our study in radiotherapy department of Military Hospital Mohamed V between January 2005 and February 2010. Despite recruits a small proportion of cancer cases, our center is accounted the one of public centers of cancer management in Morocco and we believe that our population can be considered as a 
representative sample of cases of cervical cancer who access to health system in Morocco.

\section{Conclusion}

Cervical cancer most often afflicts women in developing countries. Our study confirmed a delayed diagnosis of cervical cancer in Morocco and affirmed that menopausal status and grand multiparity were significant causal risk factor for relapse. As in the literature, advanced stages are essentially treated with concomitant radio-chemotherapy.

Despite the limitation of our study, the results may represent an important tool in guiding the actions and measures of early diagnosis of cervical cancer in Morocco.

\section{Competing interests}

The authors declare that they have no competing interests.

\section{Authors' contributions}

AM and ME, performed research and share the first position on article; AM, $\mathrm{RR}$ and $\mathrm{ME}$, analyzed data statistically; EM and $\mathrm{AM}$, collected the clinical data; $K A, A B, I L, K H, H S, B H, J K, N Z$ and $H M$, designed and coordinated research and drafted the manuscript. All authors read and approved the final manuscript.

\section{Acknowledgement}

All the authors are thankful for providing the necessary facilities for the preparation the manuscript.

Special thanks are due to the Faculty of Medicine and Pharmacy of Rabat; the source(s) of funding for all authors.

\section{Author details \\ ${ }^{1}$ Department of Radiotherapy, Mohamed V Military Hospital, Rabat, Morocco. ${ }^{2}$ National Institute of Oncology, Rabat, Morocco. ${ }^{3}$ Department of Public Health, Laboratory of Biostatics, Clinical Research and Epidemiology, School of Medicine and Pharmacy of Rabat, Rabat, Morocco. ${ }^{4}$ Department of Gynecology, Mohamed V Military Hospital, Rabat, Morocco.}

Received: 6 February 2015 Accepted: 5 May 2015

Published online: 27 July 2015

\section{References}

1. Arbyn $M$, Castellsagué $X$, de Sanjosé $S$, Bruni L, Saraiya $M$, Bray $F$, et al. Worldwide burden of cervical cancer in 2008. Ann Oncol. 2011;22(12):2675-86.

2. Ferlay J, Shin HR, Bray F, Forman D, Mathers C, Parkin DM. Estimates of worldwide burden of cancer in 2008: GLOBOCAN 2008. Int J Cancer. 2010;127(12):2893-917

3. Jemal A, Bray F, Center MM, Ferlay J, Ward E, Forman D. Global cancer statistics. CA Cancer J Clin. 2011;61(2):69-90.

4. Nelson DE, Bohen J, Marcus S, Wells HE, Meissner H. Cancer screening estimates for US metropolitan areas. Am J Prev Med. 2003;24(4):301-9.

5. Coughlin SS, King J, Richards TB, Ekwueme DU. Cervical cancer screening among women in metropolitan areas of the United States by individual-level and area-based measures of socioeconomic status, 2000 to 2002. Cancer Epidemiol Biomarkers Prev. 2006;15:2154-60.

6. Singh G, Miller B, Hankey B, Edwards B. Persistent socioeconomic disparities in US incidence of cervical cancer, mortality, stage and survival, 1975, 2000 Cancer. 2004;101:1051-7.

7. Vinh-Hung V, Bourgain C, Vlastos G, Cserni G, De Ridder M, Storme G, et al. Prognostic value of histopathology and trends in cervical cancer: a SEER population study. BMC Cancer. 2007;7:164

8. Chen SW, Liang JA, Yang SN, Ko HL, Lin FJ. The adverse effect of treatment prolongation in cervical cancer by high-dose-rate intracavitary brachytherapy. Radiother Oncol. 2003:67(1):69-76.

9. Choan E, Dahrouge S, Samant R, Mirzaei A, Price J. Radical radiotherapy for cervix cancer: the effect of waiting time on outcome. Int J Radiat Oncol Biol Phys. 2005;61(4):1071-7.
10. Bouchbika Z, Haddad H, Benchakroun N, Eddakaoui H, Kotbi S, Megrini A, et al. Cancer incidence in Morocco: report from Casablanca registry 2005-2007. Pan Afr Med J. 2013;16:31

11. Barillot I, Horiot JC, Pigneux J, Schraub S, Pourquier H, Daly N, et al. Carcinoma of the intact uterine cervix treated with radiotherapy alone: a French cooperative study: update and multivariate analysis of prognostics factors. Int J Radiat Oncol Biol Phys. 1997;38(5):969-78.

12. Fyles AW, Pintilie M, Kirkbride P, Levin W, Manchul LA, Rawlings GA. Prognostic factors in patients with cervix cancer treated by radiation therapy: results of a multiple regression analysis. Radiother Oncol. 1995;35(2):107-17.

13. Berraho M, Obtel M, Bendahhou K, Zidouh A, Errihani H, Benider A, et al. Sociodemographic factors and delay in the diagnosis of cervical cancer in Morocco. Pan Afr Med J. 2012;12:14. Epub 2012 May 25.

14. Berraho M, Bendahhou K, Obtel M, Zidouh A, Benider A, Errihani H, et al. Cervical cancer in Morocco: epidemiological profile from two main oncological centers. Asian Pac J Cancer Prev. 2012;13(7):3153-7.

15. Missaoui N, Hmissa S, Trabelsi A, Frappart L, Mokni M, Korbi S. Cervix cancer in Tunisia: clinical and pathological study. Asian Pac J Cancer Prev. 2010;11(1):235-8

16. Lankoande J, Sakande B, Ouedraogo A, Ouedraogo C, Ouatara T, Bonane B, et al. Le cancer du col utérin: aspects épidémiocliniques et anatomopathologiques. Med Afr Noire. 1998;45(7):442-5.

17. Pignon $\mathrm{T}$, Ratovonarivo H, Rafaramino F, Ruggieri S. La curiethérapie dans le traitement des cancers du col utérin à Madagascar. Bull Cancer Radiother. 1993;80:118-24.

18. Kumar R, Chauhan A, Jana S, Dadparvar S. Positron emission tomography in gynecological malignancies. Expert Rev Anticancer Ther. 2006;6:1033.

19. Rajendran JG, Greer BE. Expanding role of positron emission tomography in cancer of the uterine cervix. J Natl Compr Canc Netw. 2006;4:463.

20. Wolfson AH. Magnetic resonance imaging and positron-emission tomography imaging in the 21 st century as tools for the evaluation and management of patients with invasive cervical carcinoma. Semin Radiat Oncol. 2006;16:186.

21. Sironi S, Buda A, Picchio M, Perego P, Moreni R, Pellegrino A, et al. Lymph node metastasis in patients with clinical early-stage cervical cancer: detection with integrated FDG PET/CT. Radiology. 2006;238:272-9.

22. Perez CA, Grigsby PW, Nene SM, Camel HM, Galakatos A, Kao MS, et al. Effect of tumor size on the prognosis of carcinoma of the uterine cervix treated with irradiation alone. Cancer. 1992;69(11):2796-806.

23. Rose PG, Java J, Whitney CW, Stehman FB, Lanciano R, Thomas GM, et al. Nomograms predicting progression-free survival, overall survival, and pelvic recurrence in locally advanced cervical cancer developed from an analysis of identifiable prognostic factors in patients from NRG ncology/Gynecologic Oncology Group randomized trials of chemoradiotherapy. J Clin Oncol. JCO.2014.57.7122. [Epub ahead of print].

24. Fagundes H, Perez CA, Grigsby PW, Lockett MA. Distant metastases after irradiation alone in carcinoma of the uterine cervix. Int J Radiat Oncol Biol Phys. 1992;24(2):197-204.

25. Ponten J, Adami HO, Bergstrom R, Dillner J, Friberg LG, Gustafsson L, et al. Strategies for global control of cervical cancer. Int J Cancer. 1995;60(1):1-26.

26. Sparen $\mathrm{P}$, Gustafsson L, Friberg LG, Pontén J, Bergström R, Adami HO Improved control of invasive cervical cancer in Sweden over six decades by earlier clinical detection and better treatment. J Clin Oncol. 1995;13(3):715-25.

27. Jacqueme B, Coudert C, Mabriez JC, Bonnier P, Piana L. Antécédents de dépistage cytologique chez les patientes traitées pour cancer infiltrant du col de l'utérus. Bull Cancer. 2002;89(2):234-40.

28. Gien LT, Beauchemin MC, Thomas G. Adenocarcinoma: a unique cervical cancer. Gynecol Oncol. 2010;116(1):140-6.

29. Karimi Zarchi M, Akhavan A, Fallahzadeh H, Gholami H, Dehghani A, Teimoori S. Outcome of cervical cancer in Iranian patients according to tumor histology, stage of disease and therapy. Asian Pac J Cancer Prev. 2010;11(5):1289-91.

30. Smith HO, Tiffany MF, Qualls CR, Key CR. The rising incidence of adenocarcinoma relative to squamous cell carcinoma of the uterine cervix in the United States: a 24-year population-based study. Gynecol Oncol. 2000;78(2):97-105.

31. Wang SS, Sherman ME, Hildesheim A, Lacey Jr JV, Devesa S. Cervical adenocarcinoma and squamous cell carcinoma incidence trends among white women and black women in the United States for 1976-2000. Cancer. 2004;100(5):1035-44. 
32. Resbeut M, Fondrinier E, Fervers B, Haie-Meder C, Bataillard A, Lhommé C, et al. Standards, Options and Recommendations for the management of invasive cervical cancer patients (non metastastic). Bull Cancer. 2003;90(4):333-46.

33. Mignotte $H$, Perol $D$, Fontanière $B$, Nachury LP, Blanc-Jouvand A, Fouillat $V$, et al. Cervical cancer screening for high risk women: is it possible? Results of a cervical cancer screening program in three suburban districts of Lyon. Bull Cancer. 1999;86(6):573-9.

Submit your next manuscript to BioMed Central and take full advantage of:

- Convenient online submission

- Thorough peer review

- No space constraints or color figure charges

- Immediate publication on acceptance

- Inclusion in PubMed, CAS, Scopus and Google Scholar

- Research which is freely available for redistribution 